\title{
Malignant Brain Neoplasm
}

National Cancer Institute

\section{Source}

National Cancer Institute. Malignant Brain Neoplasm. NCI Thesaurus. Code C3568.

A primary or metastatic malignant neoplasm affecting the brain. 